\title{
Online-Offline: An Exploratory Study on the Relationship between Social Media Use and Positive Mental Health during the COVID-19 Pandemic
}

\author{
Christina Lauri, Lorleen Farrugia, Mary Anne Lauri \\ Department of Psychology, University of Malta, Msida, Malta \\ Email: mary-anne.lauri@um.edu.mt
}

How to cite this paper: Lauri, C., Farrugia, L., \& Lauri, M. A. (2022). Online-Offline: An Exploratory Study on the Relationship between Social Media Use and Positive Mental Health during the COVID-19 Pandemic. Open Journal of Social Sciences, 10, 155-170.

https://doi.org/10.4236/jss.2022.102010

Received: December 4, 2021

Accepted: February 14, 2022

Published: February 17, 2022

Copyright $\odot 2022$ by author(s) and Scientific Research Publishing Inc. This work is licensed under the Creative Commons Attribution International License (CC BY 4.0).

http://creativecommons.org/licenses/by/4.0/ (c) (i) Open Access

\begin{abstract}
Most studies on the use of social media address the effects associated with excessive use, focusing on the length of time spent online. The motivations for using social media and the type of apps used are not always given due importance. This study focuses on the users' emotional connections to social media and positive mental health. It investigates social media use as a normal behaviour used as part of a routine and also for social connectedness during the COVID-19 pandemic. These constructs are measured using two scales, the Social Media Use scale and the Positive Mental Health scale. Other questions on types of social media apps used and the reasons why they are used are also asked. Data from a volunteer sample $(n=631)$ of Maltese adults of ages between 16 and 65+, showed that while there is no association between routine use of social media and positive mental health, there is a significant negative correlation between emotional connectedness of social media use and positive mental health. The data also showed that the negative association varies across age cohorts with younger people having less positive mental health scores. This study suggests that the link between social media use and positive mental health is more complex than just measuring time spent online and effects on mental health outcomes.
\end{abstract}

\section{Keywords}

Social Media, Social Media Apps, Positive Mental Health, Social

Connectedness, Routine Use, COVID-19 Pandemic

\section{Introduction}

The internet has become part of our lives. Technological devices have become 
objects that we cannot live without, especially during the past 20 months of the pandemic when most work and education were shifted online. Our phones are with us everywhere, they are the first thing we use when we wake up and the last thing we use before we go to sleep. We touch our phones all the time. They have become extensions of us (Peper \& Harvey, 2018). The experience of meeting people face-to-face and meeting them online has been blurred and the boundary of being online and offline is not so clear all the time. Sometimes a conversation which starts face-to-face, transitions into an online continuation seamlessly. The internet and social media come with their benefits when used well. They can be very helpful in many ways. They can be used to keep in contact with relatives and friends at all times. It is used to shop online for groceries, medicines, toys, appliances, furniture or clothes. Social media are part of our lives (Nabi et al., 2013; Whiting \& Williams., 2013; Kim \& Kim, 2017).

This study is based on the work by Bekalu et al. (2019). In their study these researchers distinguished between using social media integrated into a routine referred to as "routine use" as opposed to using social media as a means to make new friends, maintain friendships and receive emotional feedback and support. The latter is referred to as "social integration and emotional connectedness use" for short referred to "emotional connectedness use". Their study found that while routine social media use is linked to positive mental health outcomes, emotional connectedness use is linked to negative health outcomes. The Positive Mental Health Scale (Lukat et al., 2016) will be used to investigate whether social media use, be it routine use or used for emotional connectedness, has any association with positive mental health using a Maltese sample of participants.

The literature on the connection between the use of social media and mental health is broadly divided into at least two approaches. One focuses on the problematic use of social media and associated effects that come with it. The other considers the use of social media as a normal social behaviour with its negative and positive outcomes on our mental health (Bekalu et al., 2019). This study falls within the second approach.

The literature on problematic use is about how social media can sometimes be used in a bad way. Cyberbullying and creating fake news are two ways how such media can be used to harm people. When used positively, social media enables individuals to draw on information and other resources such as social support from other members of the network or group (Viswanathan et al., 2018). Social media can be used for a variety of reasons including online shopping, entertainment, education, work and maintaining interpersonal relationships (Ifinedo, 2016). Social networking allows users to communicate with thousands of people all over the world (Williams et al., 2012). This has been made easier through new technologies such as smartphones.

The smartphone has revolutionized the use of social media. A study by Winneck in 2016 showed that smartphones became so much a part of us that people touch their phones at least around 2617 times a day. When this study was later repeated in 2018, it was found that many people never stop touching their 
phones even when they are off (Schaposnik \& Unwin, 2018). Smartphones have become extensions of our bodies (Peper \& Harvey, 2018). They are with us whether we are online or offline, whether we are awake or asleep.

Social norms are strong determinants of human behaviour. This is true even in the online world (Masur et al., 2021). Many people are susceptible to social influence online just as they are influenced in their offline social world (Chung \& Rimal, 2016, Dogruel \& Schnauber-Stockmann, 2021). Social media are strong normative mechanism which can influence people positively or negatively in many ways (Rimal \& Lapinski, 2015).

\section{Uses and Gratifications Theory}

Uses and Gratifications Theory, proposed by Blumler \& McQuail in 1969 explained that viewers and listeners made their own choices as to which media they chose to use, depending on which needs they needed gratified. This theory proposed that "the audience member makes a conscious and motivated choice among channels and content on offer" (McQuail, 1994: p. 318). The theory has been applied to the new media including social networking sites such as Facebook, YouTube, and TikTok. Sociological, psychological and environmental factors influence the type of media people choose to use. This applies to the new media as well (McQuail, 2005, Ruggiero, 2000). Several studies have been carried out on the uses and gratifications afforded by the new media (Dunne et al., 2010; Arnett, 2014). Whiting and Williams (2013) identify the following gratifications obtained by social media.

Uses and Gratifications of new media, adapted from Whiting and Williams (2013)

\begin{tabular}{|c|c|}
\hline Social interaction & $\begin{array}{l}\text { The use of social media to communicate and engage with } \\
\text { people }\end{array}$ \\
\hline Information seeking & $\begin{array}{l}\text { The use of social media to look for information or } \\
\text { self-educate }\end{array}$ \\
\hline Pass time & $\begin{array}{l}\text { The use of social media to keep one occupied and to ease } \\
\text { boredom }\end{array}$ \\
\hline Entertainment & $\begin{array}{l}\text { The use of social media to contribute to enjoyment and } \\
\text { entertainment such as listening to music }\end{array}$ \\
\hline Relaxation & Making use of social media to relieve anxiety and stress \\
\hline Communicatory utility & $\begin{array}{l}\text { Social media to facilitate communication and disseminate } \\
\text { information. }\end{array}$ \\
\hline Convenience & $\begin{array}{l}\text { providing users with convenience or utility such as online } \\
\text { shopping }\end{array}$ \\
\hline
\end{tabular}

\section{Social Media Use and Wellbeing}

Different forms of social media have been associated positively with indices of psychological wellbeing, such as life satisfaction and self-esteem (Ellison et al., 
2007; Nabi et al., 2013). Ellison et al., (2007) found that within a group, the members are able to stay in contact with one another even after disconnecting from one another physically. Interacting online is a continuation of meeting face-to-face. The online-offline boundary is not rigid. This is possible through online network tools. By the group staying in contact virtually after disconnecting physically they are benefiting from support from friends and a form of social capital (Ellison et al., 2007).

Several studies have found positive associations between social media use and positive mental health. Kim and Kim (2017) found that social media can have a positive association with the communication network of university students which, in succession, is also related positively to subjective wellbeing and social capital. Ostic et al., 2021 confirm that the overall impact of social media on wellbeing is positive, particularly because of the role of bonding and bridging social capital.

Although there are various studies supporting the evidence that social media and well-being are positively associated, there are several other studies that show the opposite. Findings from longitudinal studies (Coyne et al., 2020; Beeres et al., 2021) did not confirm associations between increased social media use and an increase in mental health issues in adolescents, disputing several findings that highlight this association. It seems that the relationship between mental health and social media can be complex. When social media is used well it can increase the positive mental health of users. When used excessively, on the other hand, it can create problems and therefore it affects the wellbeing of users negatively. One such study by Islam et al. (2020), discusses social media fatigue during COVID-19. Bailenson (2021) found similar results.

\section{Positive Mental Health}

Mental health is characterised by emotional wellbeing, freedom from anxiety and the ability to cope with the ordinary demands and stresses of life (APA, 2020). Over the past two decades, a greater emphasis has been placed on recognizing health and determining what makes people happy. Dolan et al., (2008) found that happiness and life satisfaction were the most popular indicators of personal health across nineteen vast datasets they examined. Studies and reports are broadening the concept of wellbeing. Subjective positive mental health, according to Diener (2006), is an umbrella term for people's various valuations of their lives, events that happen to them, the state of their minds and bodies and the conditions in which one is living.

Bekalu et al. (2019) argued that irrespective of frequency and duration of media use, there could be an association between the reasons why persons use social media, and mental health depending on the motivations and gratifications. These two other variables have not been given due importance and there is insufficient research on how variables related to social media use may have an association with mental health. The aim of this research was to find out more about this association. 
The main research question was "Is there an association between motivation for social media use and positive mental health"? Other questions investigated were:

1) Which are the most commonly used social media apps?

2) Why do participants use social media apps?

3) Is there an association between social media use and positive mental health?

\section{Questionnaire Design}

The online anonymous questionnaire consisted of 23 closed ended questions and one open ended question. The questionnaire incorporated two scales - Social Media Use Scale and The Positive Mental Health Scale.

Social Media Use Scale. Social Media Use was adapted from the Social Media Use Integration Scale by Jenkins-Guarnieri et al. (2012) and consisted of 10 questions each of which had to be answered on a 5-point Likert-type scale ( $1=$ strongly disagree to $5=$ strongly agree). This scale was made up of two subscales. The Integration into Social Routines subscale (ISR) consisted of four questions asking whether social media were integrated into one's everyday routine. It contained questions like "I don't like to use social media" and "Using social media is part of my everyday routine". The second subscale, the Social Integration and Emotional Connection Subscale (SIEC) asked six questions on whether social media use was related to emotional investment, with questions like "Social media plays an important role in my social relationships" and "I feel disconnected from friends when I have not logged into social media”. The Social Media Use Scale has been developed and tested through rigorous procedures confirming its internal reliability and validity (Bekalu et al., 2019).

The Positive Mental Health Scale. The second scale was the Positive Mental Health Scale by Lukat et al. (2016). It consisted of 9 questions measured on a 5-point Likert-scale ( $1=$ strongly disagree to $5=$ strongly agree). Questions included items like "Much of what I do brings me joy" and "I am often carefree and in good spirits". Bekalu et al., (2019) obtained values of Cronbach's alpha of 0.90 and 0.91 for the ISR and SIEC subscales, respectively, and alpha $=0.94$ for the Positive Mental Health Scale.

The final section of the questionnaire consisted of an open-ended question. Respondents were given a list of most commonly used apps and they had to choose the five apps they used most often and give reasons for why they use these apps.

A pilot study was conducted and feedback incorporated. Permission to carry out the survey was given by the Faculty Research Ethics Committee (FREC) of the University of Malta.

\section{Recruitment of Participants}

The questionnaire was shared on social media platforms to obtain data from 
participants with a wide age range and a diverse educational background. The questionnaire link was posted on the researchers' Facebook profiles. Respondents were encouraged to share the link on their own social media so that there was a snowball effect (Naderifar et al., 2017). The questionnaire was online between the $10^{\text {th }}$ of April 2021 and the $10^{\text {th }}$ of May 2021. A total of 631 participants answered the questionnaire.

\section{Results}

Table 1 describes the participants in terms of age, gender and education. This is a non-random sample and is not representative of the population. The sample is under represented in the 26 - 35 age bracket and over represented in participants having a higher and tertiary education. Since this questionnaire was put on social media, the sample collected was a volunteer sample and therefore cannot be generalized to the population. It is also over represented in females. Studies repeatedly find that women use social media more than men (e.g. Krasnova et al., 2017; Anderson \& Jiang, 2018). It could be that more women came across the questionnaire which was shared through social media platforms.

\section{Use of Social Media Apps}

Respondents were asked why they use social media apps and to mention the five social apps which they used most often. Table 2 gives, for each app, the number of participants who indicated that they were frequent users of the app. These numbers are broken down by gender and age group. The five most popular apps amongst the participants of this study were Facebook, Messenger, WhatsApp, YouTube and Instagram.

Table 1. Age, gender, and highest level of education of participants.

\begin{tabular}{ccccccc}
\hline \multirow{2}{*}{ AGE GROUPS } & \multicolumn{2}{c}{ MALES } & \multicolumn{2}{c}{ FEMALES } & \multicolumn{2}{c}{ TOTAL } \\
\cline { 2 - 7 } & $\mathrm{n}$ & $\%$ & $\mathrm{n}$ & $\%$ & $\mathrm{n}$ & $\%$ \\
\hline $16-25$ & 54 & 9 & 132 & 21 & 186 & 30 \\
$26-35$ & 22 & 4 & 60 & 10 & 82 & 13 \\
$36-45$ & 37 & 6 & 86 & 14 & 123 & 20 \\
$46+$ & 72 & 12 & 163 & 26 & 235 & 38 \\
TOTAL & 185 & 30 & 441 & 70 & 626 & 100 \\
PRIMARY & 0 & 0 & 1 & 0.1 & 1 & 0.1 \\
SECONDARY & 10 & 2 & 29 & 5 & 39 & 6 \\
POST-SECONDARY & 34 & 5 & 67 & 11 & 101 & 16 \\
HIGHER \& TERTIARY & 140 & 23 & 341 & 55 & 481 & 77 \\
TOTAL & 184 & 30 & 438 & 70 & 622 & 100 \\
\hline
\end{tabular}

Base for percentages: Whole sample. Some totals do not tally because a few respondents did not give an answer. 
Table 2. Frequent users of social media apps by gender and age.

\begin{tabular}{|c|c|c|c|c|c|c|c|c|c|c|c|c|c|c|}
\hline \multirow{2}{*}{ Apps } & \multicolumn{2}{|c|}{ Males } & \multicolumn{2}{|c|}{ Females } & \multicolumn{2}{|c|}{$16-25$} & \multicolumn{2}{|c|}{$26-35$} & \multicolumn{2}{|c|}{$36-45$} & \multicolumn{2}{|c|}{$46+$} & \multicolumn{2}{|c|}{ Total } \\
\hline & $\mathbf{N}$ & $\%$ & $\mathrm{n}$ & $\%$ & $\mathbf{n}$ & $\%$ & $\mathbf{n}$ & $\%$ & $\mathbf{N}$ & $\%$ & $\mathbf{n}$ & $\%$ & $\mathbf{n}$ & $\%$ \\
\hline Facebook & 176 & 28 & 398 & 63 & 148 & 23 & 80 & 13 & 122 & 19 & 226 & 36 & 576 & 91 \\
\hline Messenger & 169 & 27 & 404 & 64 & 181 & 29 & 70 & 11 & 111 & 18 & 212 & 34 & 574 & 91 \\
\hline WhatsApp & 135 & 21 & 369 & 58 & 93 & 15 & 72 & 11 & 115 & 18 & 226 & 36 & 506 & 80 \\
\hline YouTube & 149 & 24 & 279 & 44 & 103 & 16 & 53 & 8 & 89 & 14 & 184 & 29 & 429 & 8 \\
\hline Instagram & 86 & 14 & 251 & 40 & 170 & 27 & 56 & 9 & 40 & 6 & 71 & 11 & 337 & 53 \\
\hline Spotify & 67 & 9 & 157 & 25 & 104 & 16 & 37 & 6 & 29 & 5 & 54 & 9 & 224 & 35 \\
\hline Pinterest & 13 & 2 & 130 & 21 & 21 & 3 & 19 & 3 & 37 & 6 & 66 & 10 & 143 & 23 \\
\hline TikTok & 37 & 6 & 91 & 14 & 90 & 14 & 14 & 2 & 3 & 0.4 & 21 & 3 & 128 & 20 \\
\hline Twitter & 29 & 5 & 31 & 5 & 18 & 3 & 6 & 1 & 17 & 3 & 19 & 3 & 60 & 10 \\
\hline SnapChat & 2 & 0.3 & 15 & 2 & 11 & 2 & 2 & 0.3 & 1 & 0.1 & 2 & 0.3 & 17 & 3 \\
\hline Tinder & 7 & 1 & 6 & 1 & 7 & 1 & 4 & 1 & 1 & 0.1 & 1 & 0.1 & 13 & 2 \\
\hline
\end{tabular}

Base for percentages: whole sample (631 respondents).

\section{Reasons Why Participants Use Social Media}

Participants were asked to give three reasons why they use social media apps. Responses were analysed using thematic analysis (Braun \& Clark, 2006). The responses were read several times and given a code. Responses with similar codes were grouped into themes. These themes were then grouped into two categories basing this categorization on the work by Bekalu et al. (2019), "Routine Use" and "Emotional Connectedness".

Table 3 gives the nine themes which emerged and the codes related to them. It also gives examples of quotes given by participants.

The themes emerging from this analysis replicate the findings of various researchers (e.g. Whiting \& Williams, 2013; Sundar \& Limperos, 2013) who used Uses and Gratifications Theory to analyse the motivations people have for using social media.

\section{Routine Use and Emotional Connectedness Use}

Bekalu et al. (2019) found that "while routine use was found to be associated with positive health outcomes, emotional connection was associated with negative health outcomes" (p 795). Following Bekalu et al. (2019), three scores were computed from the data gathered. In this study the variables were called EmotionalConnectednessUse, RoutineUse, and PositiveMentalHealth, respectively.

The score for EmotionalConnectednessUse was calculated as the average of the responses from question 4 - 9 of the questionnaire, while RoutineUse was computed as the average of the responses to questions 10 to 13. Question 11 was reverse coded. PositiveMentalHealth was computed as the average of the 
Table 3. Motivations for using social media apps.

\begin{tabular}{|c|c|c|c|c|}
\hline CATEGORIES & THEMES & & Codes & Quotes \\
\hline \multirow{7}{*}{ ROUTINE USE } & $\begin{array}{l}\text { Convenience } \\
\text { and utility }\end{array}$ & $\begin{array}{l}\text { Online shopping } \\
\text { Free calls } \\
\text { Look for locations } \\
\text { Fast to message } \\
\text { Video calls } \\
\text { Efficient } \\
\text { Communicate easily }\end{array}$ & $\begin{array}{c}\text { Convenient } \\
\text { Government services } \\
\text { Jellyfish update } \\
\text { Banking } \\
\text { Google translate } \\
\text { Communicate directly }\end{array}$ & $\begin{array}{l}\text { "I use social app to buy groceries" } \\
\text { "I am partially deaf. It helps me } \\
\text { communicate" } \\
\text { "I follow mass and prayer when } \\
\text { church are closed" } \\
\text { "To communicate with } \\
\text { friends/family-find it useful e.g. } \\
\text { I am studying for an exam and } \\
\text { need some quick help/ask mum } \\
\text { if food is done" } \\
\text { "Get information on shopping offers } \\
\text { etc" }\end{array}$ \\
\hline & & & & $\begin{array}{l}\text { "Assisting students with their math } \\
\text { problems" }\end{array}$ \\
\hline & & Research papers & School & "Discuss assignments" \\
\hline & Education & $\begin{array}{c}\text { Worksheets } \\
\text { Teach } \\
\text { Books } \\
\text { Sharing documents } \\
\text { Listen to talks }\end{array}$ & $\begin{array}{l}\text { Facilitate studying } \\
\text { Discuss } \\
\text { Assignment } \\
\text { Lecture } \\
\text { Academia }\end{array}$ & $\begin{array}{l}\text { "I follow several educational pages } \\
\text { (ex: science, teaching, health, } \\
\text { geography, gardening, that keeps me } \\
\text { updated with new/interesting } \\
\text { information - and I can ask a } \\
\text { question and have it answered by a } \\
\text { number of people" }\end{array}$ \\
\hline & $\begin{array}{l}\text { Information } \\
\text { seeking }\end{array}$ & $\begin{array}{l}\text { Look for advice } \\
\text { Bus routes } \\
\text { Gozo Ferry } \\
\text { Property } \\
\text { Second hand goods }\end{array}$ & $\begin{array}{c}\text { News } \\
\text { Gardening } \\
\text { Recipes } \\
\text { Easy access to information }\end{array}$ & $\begin{array}{l}\text { "Social media apps } \\
\text { (mostly Facebook) updates me } \\
\text { regarding what is happening in the } \\
\text { outside world." } \\
\text { "ideas for crafts and lacemaking, } \\
\text { knitting and crochet" } \\
\text { "Enjoy browsing the marketplace } \\
\text { listings" }\end{array}$ \\
\hline & Work & $\begin{array}{c}\text { Advertise } \\
\text { Income } \\
\text { Work purposes }\end{array}$ & $\begin{array}{c}\text { Work updates } \\
\text { Marketing outreach } \\
\text { My job }\end{array}$ & $\begin{array}{l}\text { "For work, I am a journalist so } \\
\text { looking for stories on social media is } \\
\text { my main role" } \\
\text { "WhatsApp is mainly used for work } \\
\text { purposes, to keep in touch with } \\
\text { colleagues especially considering } \\
\text { that we have been split into } \\
\text { clusters during the pandemic." }\end{array}$ \\
\hline & $\begin{array}{l}\text { Relaxation \& } \\
\text { Entertainment }\end{array}$ & $\begin{array}{l}\text { Fun videos } \\
\text { Celebrity gossip } \\
\text { Influencers } \\
\text { TikTok } \\
\text { Leisure } \\
\text { Exercise videos } \\
\text { Watch series } \\
\text { Boredom } \\
\text { Browse Pinterest }\end{array}$ & $\begin{array}{l}\text { Unwind } \\
\text { Music } \\
\text { Hobbies } \\
\text { Posts by others } \\
\text { Browse } \\
\text { Distraction } \\
\text { Trends } \\
\text { Curiosity } \\
\text { Kill time }\end{array}$ & $\begin{array}{l}\text { "I useYouTube for all kinds of } \\
\text { information and music" } \\
\text { "Give me something to do when I } \\
\text { have some free time" } \\
\text { "They are a distraction from things } \\
\text { going on in my life, I use them as a } \\
\text { break but often end up wasting time } \\
\text { on them" }\end{array}$ \\
\hline
\end{tabular}




$\begin{array}{cc} & \text { Chat } \\ & \text { Plan outings } \\ \text { Hang out } & \text { Connect } \\ \text { with friends } & \text { Meet new people } \\ & \text { Dating } \\ & \text { Socializing } \\ & \text { Keeping tabs }\end{array}$

Offer support

Speak to family

keep connected

Advertise my work

Create content

Sharing content

Share content

Family content

Expressing
opinion

Activism

Politics

Feminist activism
"Currently in a long distance

relationship so social media is our

only means of communication even especially at the moment during

covid"

"To chat with family, friends and colleagues (especially while I was studying abroad)"

"To find old friends"

"Communicate with boyfriend"

"Checking in on family and friends daily on whatsapp and messenger instead of phone call"

"Keeps you connected with friends and family esp those who live abroad and with those who we can't meet because of the pandemic...".

"To upload our travel photos" "I post photos of my art work on Facebook"

"Sharing my material videos, photos. Learn from other people material."

"Post content which I feel are important to share" "promote mental health wellbeing and even what I like e.g.: fashion" "Promote my views and try to influence people"

responses to questions 14 to 22 of the questionnaire. High values on these scales indicated higher emotional use and routine use of social media, and higher positive mental health.

\section{Reliability and Validity}

The validity of these scales has been tested extensively (Bekalu et al., 2019). These scales were also tested for their reliability on this sample. Cronbach's alpha was calculated for the RoutineUse subscale (alpha $=0.74$ ), EmotionalConnectednessUse subscale $($ alpha $=0.82)$, and PositiveMentalHealth scale $($ alpha $=$ 0.93). It is generally regarded that a Cronbach's alpha of 0.70 and above is acceptable, a value of 0.80 and above is good and a value of 0.90 and above is excellent (George \& Mallery, 2002). In view of this the scales of reliability and validity used in the study are acceptable.

\section{Test for normality}

The scales were tested for normality. None of the three passed the test. The Shapiro-Wilks statistic had a significance of less than 0.0005 for all three scales, indicating that a normal distribution fit is very unlikely. It was therefore decided to use non-parametric tests where possible in all analysis involving these three 
scales.

\section{Correlations between the scores}

The two sub-scales, RoutineUse and EmotionalConnectednessUse were tested for correlations with Positive Mental Health using Spearman Correlation Coefficient. There was no significant correlation between RoutineUse and PositiveMentalHealth $\left(\mathrm{r}_{\mathrm{s}}=-0.05, p=0.20\right)$ but there was a significant negative correlation between EmotionalConnectednessUse and PositiveMentalHealth $\left(r_{s}=\right.$ $-0.19, p<0.0005)$. The negative correlation between emotional connection and positive mental health was also found in the study by Bekalu et al. (2019) however the positive association between routine use and positive mental health which they found in their study was not replicated here.

Figure 1 shows a scatterplot of EmotionalConnectednessUse and PositiveMentalHealth with regression lines for the four age groups.

The figure shows that for the whole sample, there is a significant negative correlation between the scores on PositiveMentalHealth and EmotionalConnectednessUse, however the negative correlation is not uniform across the age groups with that for the 16 - 25 group being the steepest.

Discussion

In this study, the three most popular apps used by the younger participants (16 - 25 years) are Instagram, Messenger and Spotify (Table 2). Possibly the reason for this could be that Instagram gives the possibility to young people to

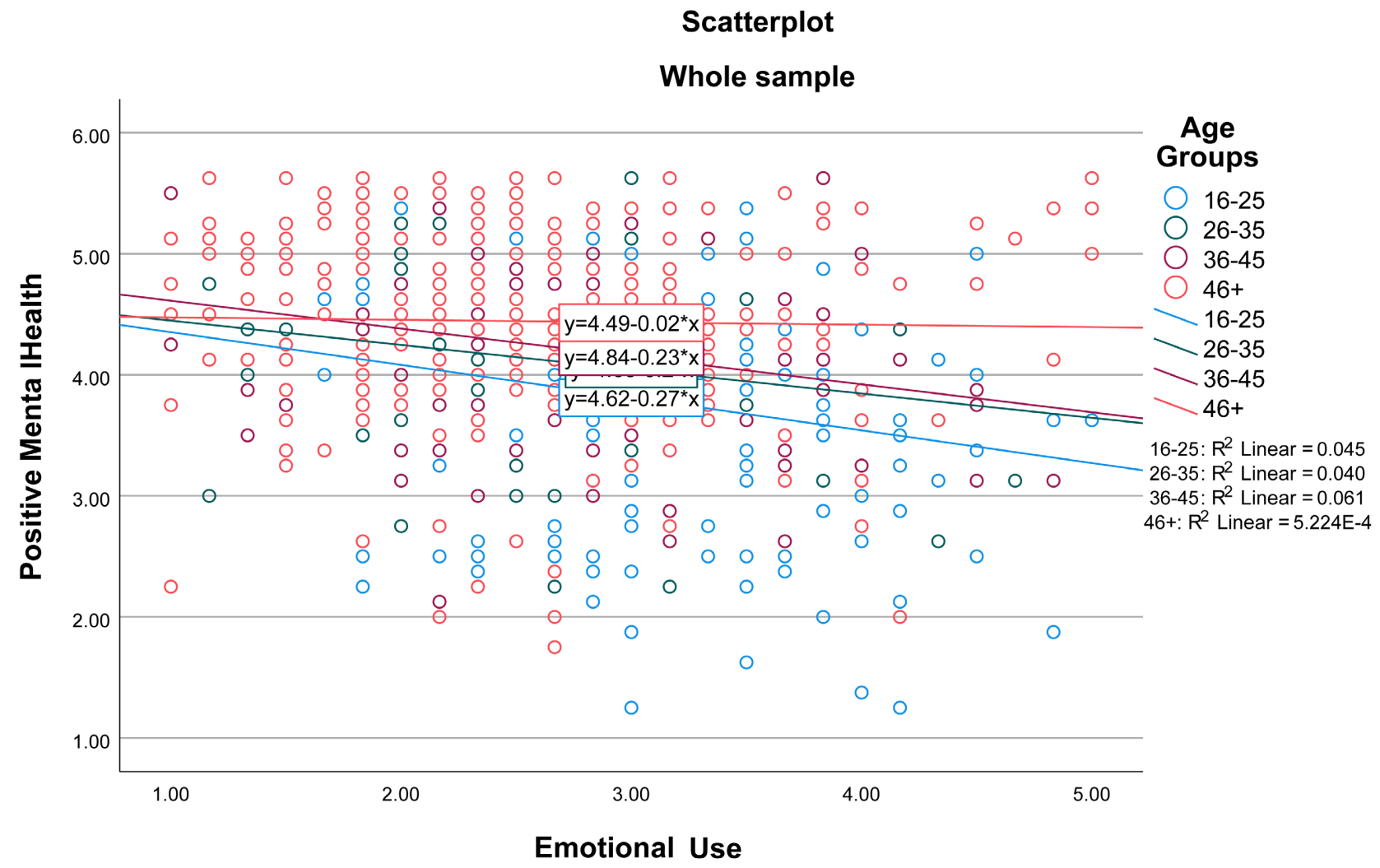

Figure 1. Scatterplot Postive Mental Health vs. Emotional Connectedness Use. 
capture every moment they choose to share with their friends without having to type a message. A picture is worth a thousand words and young people avoid writing a thousand words and instead post pictures to reach out to their friends and to feel connected to them. Even when sending messages on WhatsApp and Messenger, they use emojis and acronyms to type messages quickly. They use these social media apps to be constantly in touch with their friends. This is in line with the Social Enhancement Hypothesis which says that users make use of social networking sites to foster existing relationships and to find additional social interactions (Durbano \& Marchesi, 2016). Being online and offline becomes an unconscious transition giving young people the feeling that they are constantly with their friends.

The answers to the question "why do you use social media apps?" were many and varied. They have been classified into various themes like "to look up information", "for work", "for educational purposes", "to express opinions on various issues" and "to relax" (Table 3). Many responses were about reaching out to family, chatting, and feeling connected. These support studies using Uses and Gratifications Theory which identified new uses and needs gratified by social media (Dunne et al., 2010; Sundar \& Limperos, 2013; Whiting \& Williams, 2013). According to these studies social media helped them live a better life and increased their overall wellbeing. Similar answers were given to the open ended question in this study. Social media were important to participants to keep in touch with their friends, more so during the pandemic. Social media gave them the possibility to chat with their friends, to study and to send messages. They could not imagine going through the pandemic and lock down without social media. It helped them survive and remain in touch with their friends and with was going on around them. One participant mentioned that it was her lifeline when she was studying abroad and away from friends and family. Another participant had a boyfriend who lived abroad and she could only communicate with him through social media because she could not travel. The responses to the question of why they used social media were positive uses which enhanced one's mental health. They helped participants relax, shop, listen to music they like, look up information about their hobbies and reach out to friends and family. Some participants mentioned wasting time and none mentioned negative uses. This could possibly be a response bias to appear in good light.

There is however a negative side to using social media for emotional connectedness. Young people, and possibly older ones, try to build friendships online however those who are marginalized or ignored or who are not so popular with their friends, could feel even more lonely. This could explain the negative correlation between emotional connectedness use of social media and positive mental health (Figure 1). If young people give social media extraordinary importance in their life and if face-to-face communication is replaced by online interaction than there is the risk of feeling anxious and depressed when they feel ignored. When these interactions are not forthcoming or are totally absent, there are negative mental health repercussions. Several studies have shown that social me- 
dia use is related to stress, anxiety and depression (Krasnova et al., 2013; Shakya \& Christakis, 2017). In this study, the correlation between social media use for emotional connection and positive mental health in the younger cohort is more negative than for the other age groups (Figure 1). This implies that the younger age group, those between 16 and 24 could possibly be impacted more negatively by the use of social media than other cohorts. Possibly older age groups do not have the same needs for emotional connection as young people and the correlation between social media use for emotional connection and mental health is less negative.

Facebook seems to be more popular with older adults. WhatsApp and Messenger are also used by participants in the $46+$ years cohort (Table 2). Participants mentioned that they use them to communicate with work colleagues as well as clients. They find it convenient and useful. Some participants said they use Pinterest, Facebook and YouTube to look up short video clips to learn how to do something related to a hobby or a pastime. Similar results were found by studies such as Krasnova et al., (2017). Finding recipes was mentioned often by older participants as was information related to gardening. Crochet, lacemaking, knitting, and looking up "how to videos" were mentioned by participants indicating that social media helped them keep themselves relaxed, entertained and happy.

Results from this study show that women are more avid users of social media than men (Table 1). Various studies have found that women use social media more than men. This gender difference has been found in other studies (e.g. Krasnova et al., 2017 and Anderson \& Jiang, 2018). It seems that women use social networking sites more to explicitly foster social connections. Males seem to use social media more for looking for new relationships as opposed to maintaining relationships and to gain information of a general nature (Krasnova et al. 2017). Male participants mentioned using social media both for work as well as to relax. They also used Twitter and YouTube more frequently than other apps. This is in line with the studies by Anderson \& Jiang (2018).

\section{Routine Use of Social Media and Positive Mental Health}

One key finding in this research was that no relationship was found between routine use of social media and positive mental health. The positive correlation found by Bekalu et al. (2019) is expected since routine use includes the use of social media apps such as Tik Tok, and Spotify for relaxation and entertainment. Many participants said that they use these apps to while away the time, to relax, to chill and to listen to their favourite music. This type of media use, considered as routine use, should help foster positive mental health. Participants however also used social media for work, for school and education. The data for this research project was collected during the period when the pandemic had forced students to follow lectures online and when many workers had to work from home. This resulted in many people experiencing an increased workload and 
feeling more tired at the end of each day. The pandemic meant that there people were working online for long hours experiencing "zoom fatigue" (Bailenson, 2021). This could be a reason why the positive correlation found by Bekalu et al. (2019) between routine use and mental health was not found in this study. Whereas under normal circumstances, social media were used to keep oneself entertained, during the pandemic social media were also used for long periods of time for work and education. Thus the results were confounded by many variables which were particular to the Covid-19 situation.

\section{Emotional Connectedness Use of Social Media and Positive Mental Health}

Following the arguments made above it might be expected that emotional and connectedness use of social media would have a positive correlation with positive mental health, but in fact, a negative correlation was found, as was also found by Bekalu et al. (2019). This seems to be counter intuitive. At a time when people could not meet face-to-face, online interaction like group chats and online communication should have helped increase the morale and consequently one's positive mental health. However the results show that there was a negative correlation between emotional connectedness use of social media and positive mental health, especially among the 16 - 25 age cohort (Figure 1). It could be argued that emotional connectedness needs were not met online and that anxiety, boredom, loneliness and feelings of lack of freedom were experienced because of the fact that their online communications were not supplemented with offline interaction. Social media could not replace face-to-face contact resulting in a decrease in positive mental health.

The fact that the respondents were a volunteer sample, and therefore not representative of the population must be taken into consideration. For this reason, the results of the tests carried out have to be interpreted with caution and certainly cannot be generalised to the general population. Moreover, since the measures used were collected through self-report scales there could be inaccuracies resulting from false perceptions or other biases inherent to such scales.

\section{Concluding Note}

Literature on the links between social media use and positive mental health is inconclusive. This study has contributed preliminary data that distinguishes between routine use of social media and emotional connectedness use, thus building on the work by Bekalu et al., (2019). By using a scale which captures two dimensions of media use, this study seems to be indicating that in the case of young people, using social media for social connectedness and maintaining relationships may have negative mental health outcomes. Since the data was collected during the pandemic, and since this was a volunteer sample, the results had to be interpreted with caution. However the fact that this result was also found by Bekalu et al., (2019) is of interest. 


\section{Conflicts of Interest}

The authors declare no conflicts of interest regarding the publication of this paper.

\section{References}

American Psychological Association (APA) Dictionary of Psychology (2020). Mental Health. https://dictionary.apa.org/mental-health.

Anderson, M., \& Jiang, J. (2018). Teens, Social Media and Technology 2018. Pew Research Center: Internet, Science \& Tech. https://www.pewresearch.org/internet/2018/05/31/teens-social-media-technology-2018 1

Arnett, J. J. (2014). Emerging Adulthood: The Winding Road from the Late Teens through the Twenties (2nd ed.). Oxford University Press. https://doi.org/10.1093/acprof:oso/9780199929382.001.0001

Bailenson, J. N. (2021). Nonverbal Overload: A Theoretical Argument for the Causes of Zoom Fatigue. Technology, Mind, and Behavior, 2.

https://doi.org/10.1037/tmb0000030

Beeres, D. T., Andersson, F., Vossen, H. G., \& Galanti, M. R. (2021). Social Media and Mental Health among Early Adolescents in Sweden: A Longitudinal Study with 2-Year Follow-Up (KUPOL Study). Journal of Adolescent Health, 68, 953-960.

https://doi.org/10.1016/j.jadohealth.2020.07.042

Bekalu, M. A., McCloud, R. F., \& Viswanath, K. (2019). Association of Social Media Use with Social Well-Being, Positive Mental Health, and Self-Rated Health: Disentangling Routine Use from Emotional Connection to Use. Health Education \& Behavior, 46, 69S-80S. https://doi.org/10.1177/1090198119863768

Blumler, J. G., \& McQuail, D. (1969). Television in Politics. Its Uses and Influence. University of Chicago Press.

Braun, V., \& Clarke, V. (2006). Using Thematic Analysis in Psychology. Qualitative Research in Psychology, 3, 77-101. https://doi.org/10.1191/1478088706qp063oa

Chung, A., \& Rimal, R.N. (2016). Social Norms: A Review. Review of Communication Research, 4, 1-28. https://doi.org/10.12840/issn.2255-4165.2016.04.01.008

Coyne, S. M., Rogers, A. A., Zurcher, J. D., Stockdale, L., \& Booth, M. (2020). Does Time Spent Using Social Media Impact Mental Health? An Eight Year Longitudinal Study. Computers in Human Behavior, 104, Article ID: 106160. https://doi.org/10.1016/j.chb.2019.106160

Diener, E. (2006). Guidelines for National Indicators of Subjective Well-Being and Ill-Being. Journal of Happiness Studies, 7, 397-404.

https://doi.org/10.1007/s10902-006-9000-y

Dogruel, L., \& Schnauber-Stockmann, A. (2021). What Determines Instant Messaging Communication? Examining the Impact of Person- and Situation-Level Factors on IM Responsiveness. Mobile Media \& Communication, 9, 210-228.

https://doi.org/10.1177/2050157920943926

Dolan, P., Peasgood, T., \& White, M. (2008). Do We Really Know What Makes Us Happy? A Review of the Economic Literature on the Factors Associated with Subjective Well-Being. Journal of Economic Psychology, 29, 94-122.

https://doi.org/10.1016/j.joep.2007.09.001

Dunne, Á., Lawlor, M. A., \& Rowley, J. (2010). Young People's Use of Online Social Net- 
working Sites-A Uses and Gratifications Perspective. Journal of Research in Interactive Marketing, 4, 46-58. https://doi.org/10.1108/17505931011033551

Durbano, F., \& Marchesi, B. (Eds.) (2016). New Developments in Social Anxiety Disorders. IntechOpen. https://doi.org/10.5772/62656

Ellison, N. B., Steinfield, C., \& Lampe, C. (2007). The Benefits of Facebook “Friends:” Social Capital and College Students' Use of Online Social Network Sites. Journal of Computer-Mediated Communication, 12, 1143-1168. https://doi.org/10.1111/j.1083-6101.2007.00367.x

George, D., \& Mallery, P. (2002). SPSS for Windows Step by Step: A Simple Guide and Reference, 11.0 Update (4th Edition). Allyn \& Bacon.

Ifinedo, P. (2016). Applying Uses and Gratifications Theory and Social Influence Processes to Understand Students' Pervasive Adoption of Social Networking Sites: Perspectives from the Americas. International Journal of Information Management, 36, 192-206. https://doi.org/10.1016/j.ijinfomgt.2015.11.007

Islam, A. N., Laato, S., Talukder, S., \& Sutinen, E. (2020). Misinformation Sharing and Social Media Fatigue during COVID-19: An Affordance and Cognitive Load Perspective. Technological Forecasting and Social Change, 159, Article ID: 120201.

https://doi.org/10.1016/j.techfore.2020.120201

Jenkins-Guarnieri, M. A., Wright, S. L., \& Johnson, B. (2012). Development and Validation of a Social Media Use Integration Scale. Psychology of Popular Media Culture, 2, 38-50. https://doi.org/10.1037/a0030277

Kim, B., \& Kim, Y. (2017). College Students' Social Media Use and Communication network Heterogeneity: Implications for Social Capital and Subjective Well-Being. Computers in Human Behavior, 73, 620-628. https://doi.org/10.1016/j.chb.2017.03.033

Krasnova, H., Veltri, N., \& Eling, N. (2017). Why Men and Women Continue to Use Social Networking Sites: The Role of Gender Differences. Journal of Strategic Information Systems, 26, 261-284. https://doi.org/10.1016/j.jsis.2017.01.004

Krasnova, H., Wenninger, H., Widjaja, T., \& Buzmann, P. (2013). Envy on Facebook: A Hidden Threat to Users' Life Satisfaction? In: Proceedings of the 11th International Conference on Wirtschaftsinformatik (pp. 1-16). https://boris.unibe.ch/47080/1/WI\%202013\%20Final\%20Submission\%20Krasnova.pdf

Lukat, J., Margraf, J., Lutz, R., van der Veld, W. M., \& Becker, E. S. (2016). Psychometric Properties of the Positive Mental Health Scale (PMH-Scale). BMC Psychology, 4, Article No. 8. https://doi.org/10.1186/s40359-016-0111-X

Masur, P.K., DiFranzo, D., \& Bazarova, N.N. (2021). Behavioral Contagion on Social Media: Effects of Social Norms, Design Interventions, and Critical Media Literacy on Self-Disclosure. PLoS ONE, 16, Article ID: e0254670. https://doi.org/10.1371/journal.pone.0254670

McQuail, D. (1994). Mass Communication Theory: An Introduction. SAGE.

McQuail, D. (2005). McQuail's Mass Communication Theory(5th ed.). SAGE. https://doi.org/10.4135/9780857024374

Nabi, R. L., Prestin, A., \& So, J. (2013). Facebook Friends with (Health) Benefits? Exploring Social Network Site Use and Perceptions of Social Support, Stress, and Well-Being. Cyberpsychology, Behavior, and Social Networking, 16, 721-727. https://doi.org/10.1089/cyber.2012.0521

Naderifar, M., Goli, H., \& Ghaljaie, F. (2017). Snowball Sampling: A Purposeful Method of Sampling in Qualitative Research. Strides in Development of Medical Education, 14, Article No. e67670. https://doi.org/10.5812/sdme.67670 
Ostic, D., Qalati, S. A., Barbosa, B., Shah, S. M. M., Galvan Vela, E., Herzallah, A. M., \& Liu, F. (2021). Effects of Social Media Use on Psychological Well-Being: A Mediated Model. Frontiers in Psychology, 12, Article ID: 678766. https://doi.org/10.3389/fpsyg.2021.678766

Peper, E., \& Harvey, R. (2018). Digital Addiction: Increased Loneliness, Anxiety, and Depression. NeuroRegulation, 5, 3-8. https://doi.org/10.15540/nr.5.1.3

Rimal, R. N., \& Lapinski, M. K. (2015). A Re-Explanation of Social Norms. Ten Years Later. Communications Theory, 25, 393-409. https://doi.org/10.1111/comt.12080

Ruggiero, T. E. (2000). Uses and Gratifications Theory in the 21st Century. Mass Communication \& Society, 3, 3-37. https://doi.org/10.1207/S15327825MCS0301 02

Schaposnik, L. P., \& Unwin, J. (2018). The Phone Walkers: A Study of Human Dependence on Inactive Mobile Devices. Behaviour, 155, 389-414.

Shakya, H. B., \& Christakis, N. A. (2017). Association of Facebook Use with Compromised Well-Being: A Longitudinal Study. American Journal of Epidemiology, 185, 203-211. https://doi.org/10.1093/aje/kww189

Sundar, S. S., \& Limperos, A. M. (2013). Uses and Grats 2.0: New Gratifications for New Media. Journal of Broadcasting \& Electronic Media, 57, 504-525. https://doi.org/10.1080/08838151.2013.845827

Viswanathan, V., Malthouse, E. C., Maslowska, E., Hoornaert, S., \& van den Poel, D. (2018). Dynamics between Social Media Engagement, Firm-Generated Content, and Live and Time-Shifted TV Viewing. Journal of Service Management, 29, 378-398. https://doi.org/10.1108/JOSM-09-2016-0241

Whiting, A., \& Williams, D. (2013). Why People Use Social Media: A Uses and Gratifications Approach. Qualitative Market Research, 16, 362-369. https://doi.org/10.1108/QMR-06-2013-0041

Williams, D. L., Crittenden, V. L., Keo, T., \& McCarty, P. (2012). The Use of Social Media: An Exploratory Study among Digital Natives. Journal of Public Affairs, 12, 127-136. https://doi.org/10.1002/pa.1414 